
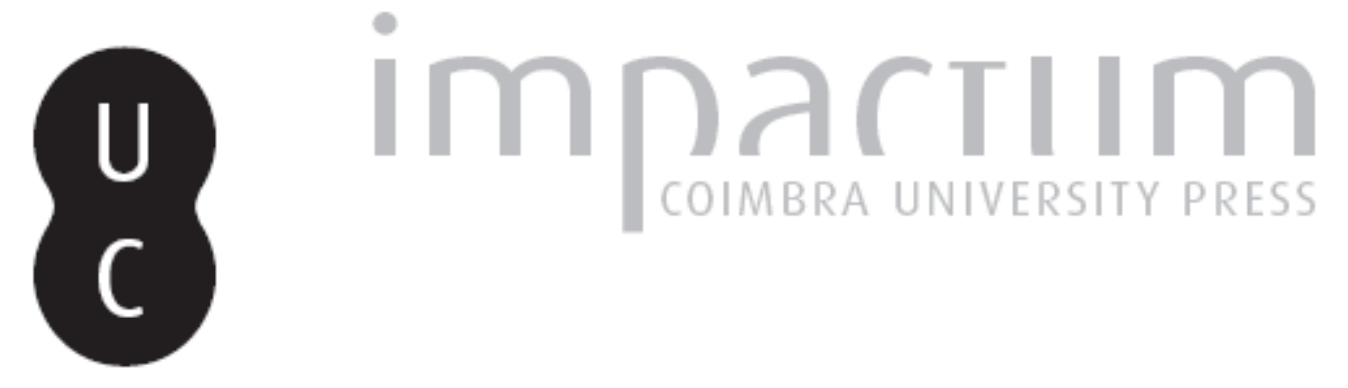

A Conimbriga Urbe ad Orbem: de Coimbra para o Mundo

Publicado por: Imprensa da Universidade de Coimbra

URL

persistente:

URI:http://hdl.handle.net/10316.2/43046

DOI:

DOI:https://doi.org/10.14195/1647-8436_46_47_24

Accessed : $\quad$ 26-Apr-2023 01:42:03

A navegação consulta e descarregamento dos títulos inseridos nas Bibliotecas Digitais UC Digitalis, UC Pombalina e UC Impactum, pressupõem a aceitação plena e sem reservas dos Termos e Condições de Uso destas Bibliotecas Digitais, disponíveis em https://digitalis.uc.pt/pt-pt/termos.

Conforme exposto nos referidos Termos e Condições de Uso, o descarregamento de títulos de acesso restrito requer uma licença válida de autorização devendo o utilizador aceder ao(s) documento(s) a partir de um endereço de IP da instituição detentora da supramencionada licença.

Ao utilizador é apenas permitido o descarregamento para uso pessoal, pelo que o emprego do(s) título(s) descarregado(s) para outro fim, designadamente comercial, carece de autorização do respetivo autor ou editor da obra.

Na medida em que todas as obras da UC Digitalis se encontram protegidas pelo Código do Direito de Autor e Direitos Conexos e demais legislação aplicável, toda a cópia, parcial ou total, deste documento, nos casos em que é legalmente admitida, deverá conter ou fazer-se acompanhar por este aviso. 


\section{BOLETIM DA \\ BIBLIOTECA GERAL DA UNIVERSIDADE DE COIMBRA}

VOL. 46/47 (2015/2016)

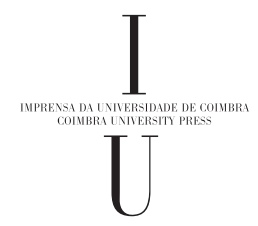




\section{A Conimbriga Urbe ad Orbem De Coimbra para o Mundo}

\section{Biblioteca Joanina, 7 de julho a 30 de outubro de 2016}

Em 1540, chegaram a Portugal os primeiros padres da Companhia de Jesus. A sua vinda correspondia a um pedido que o rei D. João III fez a Inácio de Loyola no sentido de este lhe enviar sacerdotes para a missionação da Índia. O grupo era constituído pelo italiano Paulo Camerte (Micer Paulo), pelo navarro Francisco Xavier e pelo português Simão Rodrigues. Este permaneceu no Reino, lançando as bases da Província portuguesa da Ordem, enquanto Paulo e Xavier partiram para o Oriente.

Em 1542, a Companhia criou um Colégio em Coimbra, o primeiro de uma rede de instituições semelhantes, que cobriram todo o mundo. O Colégio ficou vocacionado para a formação de missionários, como convinha a Portugal, que tinha obtido da Santa Sé o direito exclusivo da organização e financiamento de todas as atividades religiosas nos domínios e terras descobertas pela Coroa, o chamado Padroado Português do Oriente.

Nesta mostra, lembramos alguns dos milhares de Irmãos e Padres que, formados, ou apenas tendo passado por Coimbra, daqui se espalharam por todo o mundo. O Colégio de Coimbra foi um ponto de irradiação de "Cultura, Ciência e Culto" para fora da Europa. 


\section{Îndia}

Mal chegou à Índia, Francisco Xavier fundou um colégio para alunos externos (1543). O principal colégio jesuíta na Índia, Colégio de S. Paulo, anexo ao Seminário da Santa Fé de Goa, foi fundado só em 1548. Segundo o padre Simão Rodrigues, este "debía transformar-se en un segundo Coimbra, en una universidad de la Orden para filosofía e teología".

Na Índia, os jesuítas criaram a Província do Norte, Goa, e a do Sul, Malabar. Depois de 1526, tinha crescido, ao norte da Índia, o Império muçulmano dos Akbhar, relativamente tolerante às diversas religiões. Os jesuítas puderam também instalar-se em Agra, então a capital deste Império Mogol.

\section{São Francisco Xavier, 1506-1552}

Apesar da naturalidade espanhola, trabalhou sob a autoridade do Padroado e foi em português que foi escrita esta primeira biografia do "Apóstolo das Índias", ainda não canonizado nesta data.

João de Lucena, 1550-1600

Historia da vida do Padre Francisco de Xavier e do que fizerão na India os mais religiosos da Companhia de Jesu. Em Lisboa : per Pedro Crasbeek, 1600. BGUC RB-37-9

\section{Jasper Bartzoen, 1515-1553}

O holandês Barzeus foi reitor do Colégio de S. Paulo de Goa, onde privilegiava alunos indianos e onde introduziu o estudo e a prática da música ocidental.

Giovanni Pietro Maffei, 1533-1603, S.J.

Historiarvm Indicarvm libri XVI : Selectarvm item ex India epistolarum... Florentiae : apud Philippum Junctam, 1588.

BGUC S.P.-Z-14-3 
Protomártir Antonio Criminale, 1520-1549

Nascido em Parma e ordenado em Coimbra, foi Superior das missões da Costa das Pescarias e o primeiro mártir da Índia.

Daniello Bartoli, 1608-1685

Dell' Historia della compagnia di Giesv L'Asia.

In Roma : nella stamperia d'Ignatio de' Lazzeri, 1653.

BGUC 1-11-11-307

Beato António Francisco, 1553-1583

Ao que chamaram os católicos "martírio de Salsete", chamaram os indianos "revolta de Cuncolim". Foi considerada a primeira ação de resistência indiana à dominação portuguesa, no século XVI e nela foi morto António Francisco, de Coimbra, com 4 companheiros.

Daniello Bartoli, 1608-1685

Missione al Gran Mogor del Padre Ridolfo [sic] Aquaviva della Compagnia de Giesu : sua vita e morte, e d'altri quattro compagni uccisi in odio della Fede in Salsete di Goa.

Roma : Dalla Stamperia di Gio. Maria Salvioni, 1714.

BGUC R-74-37

Mártir Vicente Álvares, 1579-1606

Tinha começado os seus estudos em Coimbra, mas viria a cursar Artes no Colégio de S. Paulo de Goa. Foi Professor de Gramática em Baçaim e martirizado, aos 27 anos.

Bartolomeu Guerreiro, 1564-1642

Gloriosa coroa d'esforçados religiosos da Companhia de lesu mortos polla fe catholica...

Em lisboa : por Antonio Alvarez, 1642.

BGUC R-40-8 
São João de Brito (Arul Anandar), 1647-1693

Depois de ter feito o Noviciado em Lisboa, onde nasceu, e de ter estudado em Évora, veio completar Filosofia em Coimbra, onde Ihe nasceu a vocação missionária, que cumpriu no Madurai, até ao martírio.

Jean Marie Prat, 1809-1891

Historia de la vida y martirio del beato Juan de Britto ... muerto en odio de la fe en el reino de Marava, escrito en francés.

Madrid : Imprenta, Fundaci y Librería de D. Eusebio Aguado, 1854.

BGUC 7-40-2-115

Manuel de Figueiredo, 1688-?

Partiu de Coimbra para o Mogor, onde foi muitos anos reitor de Agra e Procurador da Província de Goa, de 1756 até à expulsão dos jesuítas, em 1759. Publicou alguns sermões, em Lisboa.

Manuel de Figueiredo, 1688- ?, S.J.

Sermam de acçam de graças pela victoria q. alcançou o ... vice-rey e capitam general da India do Bonsulo, inimigo do estado, em 5 de mayo de 1746.

Lisboa : off. de Francisco da Silva, 1747.

BGUC Misc. 270, № 4491

\section{Manuel de Sá, 1658-1728}

Deu apoio aos Vice-reis em sensíveis matérias diplomáticas, na Índia e no Ceilão. Foi nomeado correspondente da Academia Real de História Portuguesa, logo que esta foi criada (1720).

Manuel Caetano de Sousa, 1658-1734

Elogio funebre do ... Padre Manoel de Sá, da Companhia de Jesu...

"Collecçam dos documentos, estatutos, e memorias da Academia Real da Historia Portugueza". Lisboa, Vol. XIII (1728), Num. XIII.

BGUC S.P.-Ab-7-9 


\section{Cochinchina}

Desde o século XVI que os portugueses frequentavam o território que chamaram Cochinchina, constituído pelo Vietname, Camboja, Sião (atual Tailândia) e Pegú (atual Myanmar).

Por lá peregrinou Fernão Mendes Pinto e ali naufragou Luís de Camões. Mas a missionação jesuíta da região só começou em 1615 com a criação das missões do Cambodja e do Tonquim (norte do atual Vietname), a partir dos recursos desviados da perseguida missão do Japão pelo Visitador André Palmeiro.

Beato Diogo Carvalho, 1578-1624

Porque tinha estado no Japão e conhecia bem a língua, este conimbricense

foi um dos primeiros jesuítas enviados à Cochinchina para assistir aos cristãos nipónicos que aí se tinham refugiado.

Manuel Ferreira, 1630-1699, S.J.

Noticias summarias das perseguições da missam de Cochinchina, principiada, \& continuada pelos padres da Companhia de Jesu.

Em Lisboa : na Officina de Miguel Manescal, impressor do Santo Officio : impresso à sua custa, 1700.

BGUC V.T.-8-1-8

Francisco de Pina, 1585?-1625

Ofuscado pelo seu aluno Alexandre de Rhodes, foi ele o iniciador da romanização da língua vietnamita, como recentemente estabeleceu, em sólidas bases documentais e filológicas, Jacques Roland.

Alexandre de Rhodes, 1591-1660, S.J.

Tvnchinensis historiae... altero mirables evangelicae predicationis progressus referentur...

Lugduni : Ioan. Bapt. Devenet, 1652.

BGUC 1-(1)-11-4 
Christoforo Borri, 1583-1632

Matemático milanês, foi para o Vietname, onde missionou cinco anos e fez observações dos cometas de 1618. Regressado à Europa, voltou a ensinar, em Coimbra (1626/1627) e em Lisboa (1627/1628). Introduziu em Portugal o sistema ticónico.

Cristoforo Borri, 1583-1632

Collecta astronomica, ex doctrina P. Christophori Borri, Mediolanensis, ex Societate lesu. De tribus caelis, Aereo, Sydereo, Empyreo. Iussu, et studio...

Ulysipone : apud Matthiam Rodrigues, 1631 (Em Lisboa : por Matias Rodrigues, 1629).

BGUC RB-34-10

João de Loureiro, 1710?-1791

João de Loureiro, botânico e matemático atuando como médico no Vietname, fez estes registos astronómicos entre 1758 e 1774, à latitude de $16^{\circ} 30^{\prime} \mathrm{N}$ (Hué).

João de Loureiro, S.J., 1710?-1791

Observationes astronomicae.

"Memorias de Mathematica e Physica da Acad. das Sciencias de Lisboa". Lisboa, t. 3, 2a parte (1814), p. 1-6.

BGUC A-29-31

\section{China e Tibete}

O número de jesuítas na China nunca terá sido tão grande como na Índia ou no Malabar, mas a sua qualidade foi certamente superior. Eram escolhidos pelas suas capacidades científicas e praticamente todos eles passaram por Coimbra.

O Padroado Português protegeu de alguma forma a penetração dos jesuítas na China, via Macau, percebendo que a abordagem da Companhia, usando o passaporte da ciência e da tecnologia ocidentais, garantia acesso ao Imperador e às classes dirigentes chinesas 
e funcionava como proteção às Missões instaladas no restante território chinês.

Esta solução funcionou bem até que outras Ordens e outros países, que ambicionavam um acesso direto à China, intrigaram para que o Papa condenasse a accommodatio e a imitatio jesuítas, suscitando a chamada Questão dos Ritos.

Matteo Ricci (Li Madou), 1552-1610

É o mais famoso dos missionários europeus na China, onde recebeu o título honorífico de "Grande Sábio Ocidental" (Taìxī Dà Rú), pelos seus conhecimentos matemáticos e astronómicos, pela sua prodigiosa memória e pela sua habilidade artística.

Matteo Ricci, 1552-1610, S.J.

De christiana expeditione apud Sinas suscepta ab Societate lesu ... libri V ... Lugduni : sumptibus Horatii Cardon : [ex typographeio loannis lullieron], 1616.

BGUC 1-8-3-206

António de Gouveia (He Dahua), 1592?-1677

Na qualidade de vice-provincial da China, Gouveia esteve preso seis anos em Cantão (1665-1671). Quando foi libertado, compilou esta Innocentia victrix, impressa na China.

António de Gouveia, 1592?-1677, S.J.

Innocentia victrix sive Sententia Comitiorum Imperii Sinici Pro innocentia Christianae religionis lata juridicè per annum 1669.

In Quam Cheu metropoli provinciae Quam tum in Regno Sinarum [i.e. Guang-zhou] : [s.n.], 1671. Encadern. chinesa em seda lavrada.

BGUC Cofre 38

Gabriel de Magalhães (An Wensi), 1609-1677

Depois de missionar em diversos locais, foi preso, torturado, condenado à morte e, finalmente, amnistiado e solto (1664-1665). Veio a fixar-se em Pequim, onde construiu autómatos e relógios para diversão do Imperador Kangxi. 
Gabriel de Magalhães, 1609-1677, S.J.

Nouvelle relation de la Chine contenant la description des particularités les plus considérables de ce grand empire.

Paris : Claude Barbin, 1688.

BGUC V.T.-7-6-20

Ferdinand Verbiest (Nan Huairen), 1623-1688

Um dos mais prestigiados astrónomos jesuítas de Pequim foi encarregado pelo Imperador de reformar e de equipar com máquinas europeias um novo Observatório. Ele próprio foi construtor de vários dos instrumentos científicos.

Antoine Thomas, 1644-1709, S.J.

Carta acerca de la muerte del Padre Fernando Verbiest...

In: Phillipe Couplet, 1624-1693 - Historia de vna gran señora, christiana de la China, Ilamada doña Candida Hiù... En Madrid : En la Imprenta de Antonio Roman, 1691. P. 216-246.

BGUC 4-2-24-3

Tomás (ou Tomé) Pereira (Xu Risheng ou Xu Moude), 1645-1708

Foi professor do Imperador Kangxi e o introdutor da música europeia na China. Para além disso, este trecho sobre a vida de Buda condensa uma informação mais extensa por ele enviada de Pequim a Fernão de Queirós, que outrora conhecera em Goa.

Fernão de Queirós, 1617-1688, S.J.

Conquista temporal e espiritual de Ceylão.

$1^{\text {a }}$ ed. Colombo : H. C. Cottle, 1916.

BGUC 9-(4)-3-5-1

Martino Martini (Wei Kuangguo), 1614-1661

Um jesuíta completo: historiador, teólogo, matemático, geógrafo e publicista da Companhia. Concebido a partir de fontes chinesas e jesuítas, o seu Novus atlas Sinensis foi o primeiro atlas da China publicado na Europa. 
Martino Martini, 1614-1661, S.J.

Atlas nuevo de la extrema Asia, o Descripcion geographica del Imperio de los Chinas [Material cartográfico].

A Amsterdam : en costa y en casa de Juan Blaeu, 1659.

BGUC 4 A-20-10-7

Antoine Thomas (Anduo Pingshi), 1644-1709

Matemático belga que, em 1702, mediu na China o comprimento de um grau de longitude. Em 1705, mapeou a região de Pequim.

Defendeu que a liturgia pudesse celebrar-se em língua clássica chinesa.

Longitvdes d'Avignon et de Conimbre déterminées sur les observations faites... «Journal des Sçavants». Paris (1679), p. 30-31.

BGUC 10-46-1

José Soares (Su Lin), 1656-1736

Fluente em português, em latim e em chinês. Traduziu diretamente do chinês para o português este "Édito da Tolerância" (1692) do Imperador Kangxi.

José Soares, 1656-1736, S.J.

La libertad de la ley de Dios, en el Imperio de la China.

Lisboa : off. de Miguel Deslandes, 1696.

BGUC 1-11-13-68

António de Andrade, 1580-1634

Superior da Missão de Agra, no Império Mogol, ouviu falar de vestígios de Cristianismo no longínquo Tibete. Empreendeu, então, a viagem a pé, sendo o primeiro europeu a atravessar os Himalaias, em 1624. Voltou no ano seguinte, acompanhado de Manuel da Veiga, autor deste relato.

Manuel da Veiga, S.J.

Relaçam geral do estado da christandade de Ethiopia ... \& do que de nouo socedeo no descobrime[n]to do Thybet, a que chamam, gram Catayo.

Em Lisboa : por Mattheus Pinheiro, 1628.

BGUC R-1-8 


\section{Japão}

Em Macau, por 1589, escrevia-se sobre os jesuítas no Japão: “Sabemos que o nome da cidade de Coimbra (...) aparece com frequência nas conversas dos padres da Companhia de Jesus e que a saudade gostosa e a memória do Colégio Conimbricense, no qual muitos deles foram educados, se renovam repetidamente" ${ }^{\prime \prime}$.

De Coimbra partiram os primeiros missionários para o Japão. $\mathrm{E}$ para a cidade do Mondego veio estudar Bernardo de Kagoshima ( ? -1557), o primeiro japonês a pisar solo europeu, em 1553. Também em Coimbra se imprimiram pela primeira vez na Europa carateres de um texto em japonês. No regresso de Roma, a Embaixada dos Daimyōs passou por Coimbra. Daqui foi a primeira biblioteca europeia e, talvez, a primeira prensa tipográfica ocidental que imprimiu no país do Sol Nascente.

Melchior (ou Belchior) Nunes Barreto (Ba Laiduo), ca. 1520-1571

Doutor pela Universidade, foi "um homem de prodigiosa cultura", que levou de Coimbra para o Japão a primeira biblioteca europeia digna desse nome. Acompanhou-o na viagem o aventureiro Fernão Mendes Pinto.

Fernão Mendes Pinto, 1514?-1583

Peregrinaçam ...

Em Lisboa : por Pedro Crasbeeck : a custa de Belchior de Faria, 1614.

BGUC 1-6-22-500

João Rodrigues Girão, 1558?-1629

Missionário natural de Alcochete, foi coautor das Cartas Ânuas do Japão dos anos de 1604-1605, de 1606-1607 (que aqui se mostram), de 1609-

1 "Vrbis Conimbricae nomen (...) crebris usurpatum sermonibus a patribus Societatis, scimus, collegiique Conimbricensis, in quo multi ex illis educati sunt, iucundum saepe desiderium memoriamque renouari."

(Duarte de Sande - De missione... Colloqvivm trigesimum primum, 1589). 
1610 e de outras. Faleceu em Macau, a 15 de outubro de 1629 e não em 1633, como trazem muitos catálogos.

João Rodrigues Girão, 1558?-1629, e outro

Litterae laponicae anni MDCVI Chinenses anni MDCVI \& MDCVII...

Antuerpiae : Ex Officina Plantiniana : apud Viduam et Filios lo. Moreti, 1611. BGUC R-72-4

Mártir Sebastião Vieira (Wei Aila), 1572-1634

Foi procurador da Província de Macau, missionou nas Filipinas (1614) e foi eleito para ir a Roma (1623) como procurador da Província Japonesa. Em 1629, voltou ao Oriente, levando 23 jesuítas de várias nacionalidades.

Bartolomeu Guerreiro, 1564-1642

Gloriosa coroa d'esforçados religiosos da Companhia de lesu mortos polla fe catholica...

Em lisboa : por Antonio Alvarez, 1642.

BGUC V.T.-8-9-4

Mártir Francisco Borges Pacheco, 1565-1626

Ainda em jovem, conheceu a história do seu tio, o Pe. Diogo de Mesquita, martirizado no Japão. Nomeado Provincial, em 1621, acabou por ser preso em Kuchinotsu, torturado em Arima e, finalmente, queimado vivo em Nagasaki.

Bartolomeu Pereira, 1588-1650, S.J.

Paciecidos : libri duodecim ...

Conimbricae : expensis Emmanuelis de Carvalho, 1640

BGUC 4 A-16-36-12

Beato João Batista Machado, 1582-1617

Esta gravura em água-forte foi aberta por Pietro Miotte (fl. 1637-1656), em Roma, quase 30 anos depois de o Beato João Batista Machado ter sido martirizado no Japão, a 27 de maio de 1617. 
António Francisco Cardim, 1596-1659, S.J.

Fasciculus e lapponicis floribus, suo adhuc madentibus sanguine.

Romae : Typis Heredum Corbelletti, 1646.

BGUC RB-37-35

\section{África}

Desde o século XII, que o mito de um Reino cristão, governado pelo Preste João, atravessava a Europa e fascinava também os portugueses, desde o início da expansão. A Abissínia (atual Etiópia) foi atingida por terra pelo português Pero da Covilhã, entre 1491 e 1493.

As missões jesuítas àquele país, tentando converter o Negus, começaram em 1555, quando as diferenças entre o Cristianismo de Roma e a fé etíope já eram evidentes.

O esforço missionário jesuíta chegou também às praças portuguesas de Marrocos, aos reinos de Angola e do Congo, a Ormuz (atual Irão), a Moçambique e ao Monomotapa (atual Zimbabwe).

Dom Gonçalo da Silveira, 1521 ou 1523-1561

Filho do $1^{\circ}$ Conde da Sortelha, foi para a Índia, em 1556, como Provincial. Depois, para África, impulsionando as missões jesuítas em Gamba, Tongue, Inhambane e Monomotapa (Zimbabwe). Luís de Camões dedicou-Ihe o Soneto 37 das "Rimas".

Luís de Camões, 1524?-1580

Rimas. Accrescentadas nesta segunda impressão...

Em Lisboa : por Pedro Crasbeeck : a custa de Esteuão Lopez, 1598.

BGUC R-2-12

Diogo de Matos, 1588-1633?

Nasceu em Barcouço, perto de Coimbra, embarcou para a Índia em 1607 e passou à Etiópia, em 1620. Durante 7 anos, acompanhou o Rei Sūsenyōs 
nas suas campanhas, mas foi preso e deportado para Goa, quando ele morreu.

Diogo de Matos, 1588-1633?, S.J.

Copia de huma Carta em que dà conta dos successos da jornada do Emperador da Etiopia contra os villoens de hasta.

In: Baltasar Teles, S.J., 1596-1675 - Historia geral de Ethiopia a Alta, ou Preste Joam e do que nella obraram os Padres da Companhia de lesus. Em Coimbra : na Offic. de Manoel Dias, 1660. P. 475-477.

BGUC V.T.-8-8-5

Mestre Andrés de Oviedo, 1518?-1577

É lembrado como conselheiro espiritual de Francisco de Borja, que trouxe para a Companhia. Foi para a Etiópia como coadjutor do Arcebispo João Nunes Barreto. Sucedeu-Ihe no cargo e foi Bispo titular de Hierápolis (Síria).

Nicolau Godinho, 1561?-1616, S.J.

De abassinorvm rebvs, déque Aethiopiae Patriarchis loanne Nonio Barreto et Andrea Oviedo, libri tres. Nunc primùm in lucem emissi. Lugduni : Sumptibus Horatij Cardon, 1615.

BGUC R-74-28

Andrés Gualdámez (ou Galdames), 1517-1562

Tradutor de vários livros, Andrés Gualdames, como era conhecido entre os portugueses, foi natural de Xerez de la Frontera (Espanha) e o primeiro jesuíta mártir da Etiópia, morto pelos turcos, no Mar Vermelho.

Francisco de Sousa, 1649-1712, S.J.

Oriente conquistado a Jesu Christo pelos Padres da Companhia de Jesus da Provincia de Goa...

Lisboa : na Officina de Valentim da Costa Deslandes, 1710. 2 vol. BGUC V.T.-10-7-9/10 


\section{Brasil}

A importância dos jesuítas para o Brasil foi enorme. Basta pensarmos que a sua atividade missionária andou a par com a colonização, a urbanização e a sedentarização das tribos. Os seguidores de Santo Inácio ficaram ligados à fundação das cidades de Salvador (Juan de Azpilikueta), S. Paulo (José de Anchieta), Rio de Janeiro (Manuel da Nóbrega) e outras.

No vasto espaço brasileiro, também foram os jesuítas que conseguiram estabelecer uma língua indígena de comunicação, a "língua comum", de que foram os gramáticos e os primeiros dicionaristas.

Até ao decreto de expulsão, o ensino na colónia brasileira dependeu quase exclusivamente dos Inacianos.

\section{Manuel da Nóbrega, 1519-1570}

Nascido nas ilhas Canárias, obteve em Coimbra equivalência a bacharel em Cânones e Filosofia, em 1541, depois de ter frequentado 5 anos em Salamanca. Chefiou a primeira missão jesuíta ao Brasil.

Simão de Vasconcelos, 1597-1671, S.J.

Chronica da Companhia de Jesu do Estado do Brasil e do que obrarão seus filhos nesta parte do novo mundo ...

Lisboa : Na Officina de Henrique Valente de Oliueira, 1663.

BGUC V.T.-14-9-9

Beato Inácio de Azevedo, ca. 1526-1570

Foi Visitador e depois Provincial da Companhia de Jesus no Brasil e o superior de um grupo que foi martirizado por corsários franceses, em julho de 1570, junto à ilha da Palma (Canárias). 
[Duas cartas sobre a morte do padre Inácio de Azevedo].

In: Giovanni Pietro Maffei, 1533-1603, S.J. - ...Historiarvm Indicarvm libri XVI : Selectarvm item ex India epistolarum... Florentiae : apud Philippum Junctam, 1588.

BGUC 4 A-2-4-8

São José de Anchieta, 1534-1597

Natural de Tenerife, foi, ainda noviço, na armada de Duarte Góis para o Brasil. Foi o autor da primeira gramática da língua tupi. Foi recentemente santificado pelo Papa Francisco, em 2014.

José de Anchieta, S.J.,1534-1597

Arte de gramatica da língua mais usada na costa do Brasil.

Ed. facsimilar. São Paulo : Editora Anchieta, 1946.

BGUC 5-41-12

Pedro Dias, 1621-1700

Para a catequização dos escravos de etnia bantu de Salvador (Baía), os jesuítas tiveram de escolher (e de aprender) uma língua africana, o Kimbundu.

Pedro Dias, 1621-1700, S.J.

Arte da lingua de Angola...

Lisboa : na officina de Miguel Deslandes, 1697.

BGUC R-17-37

Simão Marques, 1684-1766

Chegou ao Brasil em 1702, foi Reitor do Colégio do Rio de Janeiro e aí ensinou Belas-Letras, Filosofia e Teologia. Este padre natural de Coimbra viria a ser preso e deportado para Itália, tendo morrido em Roma.

Simão Marques, 1684-1766, S.J.

Sermaõ das Santas onze mil Virgens... prégado no real Collegio da Companhia de Jesu da Cidade do Rio de Janeyro...

Lisboa Occidental: Off. de Miguel Rodrigues, 1733.

BGUC Misc. 237, № 3957 